\title{
Brief wakeful resting can eliminate directed forgetting
}

\section{Andreas Schlichting \& Karl-Heinz T. Bäuml}

To cite this article: Andreas Schlichting \& Karl-Heinz T. Bäuml (2017) Brief wakeful resting can eliminate directed forgetting, Memory, 25:2, 254-260, DOI: 10.1080/09658211.2016.1153659

To link to this article: https://doi.org/10.1080/09658211.2016.1153659

册 Published online: 29 Feb 2016.

Submit your article to this journal $₫$

Џ Article views: 182

Q View related articles $\sqsubset$

View Crossmark data $₫$

Citing articles: 1 View citing articles $\longleftarrow$ 


\title{
Brief wakeful resting can eliminate directed forgetting
}

\author{
Andreas Schlichting and Karl-Heinz T. Bäuml \\ Department of Experimental Psychology, Regensburg University, Germany
}

\begin{abstract}
When cued to intentionally forget previously encoded memories, participants typically show reduced recall of the memories on a later recall test. We examined how such directed forgetting is affected by a brief period of wakeful resting between encoding and test. Encoding was followed by a "passive" wakeful resting period in which subjects heard emotionally neutral music or perceived neutral pictures, or it was followed by an "active" distraction period in which subjects were engaged in counting or calculation tasks. Whereas typical directed forgetting was present after active distraction, the forgetting was absent after wakeful resting. The findings indicate that the degree to which people can intentionally forget memories is influenced by the cognitive activity that people engage in shortly after learning takes place. The results provide first evidence on the interplay between wakeful resting and intentional forgetting.
\end{abstract}

ARTICLE HISTORY

Received 12 March 2015

Accepted 7 February 2016

\section{KEYWORDS}

Episodic memory; directed forgetting; wakeful resting; reactivation
Humans can intentionally forget outdated memories, like a friend's old home address, and make them less retrievable in order to enhance access to more current and relevant information, that is, the friend's current home address. Such updating processes in episodic memory have been examined in the laboratory using the list-method directed forgetting (LMDF) task (e.g., Bjork, 1970). In this task, participants study a list of items and, after study, receive a cue to either forget or continue to remember that list. After study of another list, participants are asked to recall the items on the first list, irrespective of original cuing. Typically, the forget cue impairs recall of the items, relative to the remember cue, reflecting goal-directed forgetting of the obsolete precue information (for a recent review of LMDF, see Sahakyan, Delaney, Foster, \& Abushanab, 2013). ${ }^{1}$

The directed forgetting effect is mostly explained by a retrieval inhibition or context change. The retrieval inhibition account assumes that the forget cue leads to reduced accessibility of the precue items by active inhibition of the items' study context (Geiselman, Bjork, \& Fishman, 1983). The context-change account assumes that the forget cue induces a change in participants' internal context and the resulting mismatch between the contexts at encoding and test causes forgetting of the first-list items (Sahakyan \& Kelley, 2002). Although the processes underlying the forgetting effect thus are characterised as inhibitory by the one account and as noninhibitory by the other, both explain the forgetting by impaired access to the items' study context (see also Bäuml \& Samenieh, 2012a, 2012b).
In line with the impaired context access explanation, several studies have shown that the memorial effects of the forget cue on the precue items can be reduced, or even be eliminated, when the study context of the items is reactivated at test. Sahakyan and Kelley (2002), for instance, used a mental context reinstatement technique and asked participants at test to think back and write down which thoughts and feelings they had immediately before and during learning of the precue items. Doing so, participants in the forget condition showed less directed forgetting than in the absence of such context reinstatement. Bäuml and Samenieh (2010) used a selective retrieval technique and asked participants to recall predefined target items of the first list at test, either with or without preceding (cued) recall of the list's remaining (nontarget) items. The preceding recall of nontarget items reduced the forgetting of the target items, suggesting that retrieval of a some precue items can reactivate the items' study context and thus facilitate access to the remaining list items (see also Bäuml \& Samenieh, 2012b; Bjork \& Bjork, 1996).

Whereas this line of work shows that a deactivated study episode can be reactivated by effortful mental context reinstatement or active retrieval of some of the episode's items, other research areas suggest that reactivation can also occur more passively, such as during sleep or wakeful resting. Indeed, numerous studies reported evidence that regular nocturnal sleep after encoding improves memory performance relative to a wake interval of the same duration (e.g., Diekelmann, Wilhelm, \& Born, 
2009; Stickgold \& Walker, 2013). Similarly, some studies found increased recall when encoding was followed by a short period of wakeful resting compared to when it was followed by a period during which participants actively engaged in a distractor task, like a psychometric test or a spot-the-difference game (e.g., Cowan, Beschin, \& Della Sala, 2004; Dewar, Alber, Butler, Cowan, \& Della Sala, 2012). The proposal is that both sleep and wakeful resting can cause reactivation of the study episode and thus promote consolidation and later recall of the memory contents (Dewar et al., 2012; Rasch \& Born, 2013). Imaging studies support the proposal, reporting that the beneficial effects of both sleep and wakeful resting are associated with hippocampal replay of studyrelated neural activity (Rasch, Büchel, Gais, \& Born, 2007; Tambini, Ketz, \& Davachi, 2010).

If reactivation of the precue items' study context can reduce directed forgetting of these items (Sahakyan \& Kelley, 2002) and sleep after study reactivates the study episode (e.g., Rasch et al., 2007), then sleep may also reduce directed forgetting. Corresponding evidence was reported in a recent study by Abel and Bäuml (2013). Employing the LMDF task, these researchers let participants study the two lists either in the morning at 9 a.m. (wake condition) or in the evening at 9 p.m. (sleep condition). Participants in the wake condition stayed awake and took the final test at 9 p.m. in the evening of the same day. In contrast, in the sleep condition, participants were tested the following morning at 9 a.m. after a night including normal nocturnal sleep. Whereas in the wake condition, directed forgetting of the precue items was present after the $12 \mathrm{~h}$ retention interval, no forgetting arose in the sleep condition.

The goal of the present study was to examine whether wakeful resting can also reduce directed forgetting. Indeed, if reactivation of the study context can reduce items' directed forgetting, and wakeful resting after study can reactivate the study context (Dewar et al., 2012; Tambini et al., 2010), then wakeful resting may also reduce directed forgetting. To date, the results of numerous studies support the view of reactivation processes during sleep, whereas studies indicating reactivation processes during wakeful resting are limited. In particular, no study has yet examined whether wakeful resting can reduce intentional forgetting. This study thus extends the prior work in important ways, providing first information on whether intentional forgetting can be affected by the cognitive activity people engage in briefly after new learning takes place.

A standard LMDF procedure was employed to address this issue. In each of two experimental blocks, participants studied a list of items and received a cue to either remember or forget the list. After study of the second list and a short retention interval, memory for the items on the first list was tested. We manipulated the level of cognitive activity during the retention interval by employing two types of distractor tasks. We employed counting backwards and calculation tasks as common "active" distractor tasks, which require participants to perform cognitive operations (e.g., Nairne \& Healy, 1983) and in previous LMDF studies were found to induce directed forgetting (e.g., Geiselman et al., 1983; Sahakyan \& Kelley, 2002; see also Discussion). In contrast, we used hearing neutral music and perceiving neutral pictures as "passive" distractor tasks, which do not require any demanding cognitive operations and thus can induce wakeful resting. Following the view that wakeful resting can induce reactivation and consolidation of newly acquired memories (Diba \& Buzsáki, 2007; Tambini et al., 2010), we hypothesised that wakeful resting may reduce directed forgetting.

\section{Method}

Participants. Ninety-six undergraduate students (67 female) of Regensburg University participated $(M=22.9$ years, SD $=3.2$ ). They were tested individually, with 24 participants in each experimental condition.

Materials. Four study lists were constructed, each consisting of 15 unrelated concrete German nouns (Duyck, Desmet, Verbeke, \& Brysbaert, 2004). Two lists were used as List 1, and for each of the two lists, 5 items were defined as target items. Within these lists, each item had a unique initial letter. The other two lists were used as List 2.

In one of the four distractor task conditions, participants were presented with two emotionally neutral instrumental pieces of music (Aerial Boundaries by Michael Hedges and Neptune, the Mystic by Gustav Holst; e.g., Richell \& Anderson, 2004; Wood, Saltzberg, \& Goldsamt, 1990). In another condition, we used two sets of 10 pictures from the International Affective Picture System (IAPS; Lang, Bradley, \& Cuthbert, 1999). Emotional valence of the pictures was neutral $(M=4.8)$ and did not differ between the sets, $t(18)<1$. Ratings for emotional arousal showed moderate values $(M=3.6)$ and did also not differ between the sets, $t(18)<1$.

Design. The experiment had a $2 \times 4$ mixed factorial design. CUE (remember, forget) was manipulated within participants, and DISTRACTOR TASK (counting, calculations, music, and pictures) between participants. In the remember condition, study of List 1 was followed by a cue to remember the list for an upcoming memory test, whereas in the forget condition, it was followed by a cue to forget the list. After study of List 2, participants counted backwards by threes, solved simple math calculations, listened to a short piece of music, or watched a set of pictures. Order of cue conditions, as well as assignment of lists to conditions, were counterbalanced.

Procedure. The procedure is shown in Figure 1(a).

Study Phase. In each experimental condition, list items were exposed individually at a $4 \mathrm{~s}$ rate in a random order. Presentation of List-1 items was followed by a cue to remember the items for an upcoming test, or a software 
(a)

$$
\text { Study Phase }
$$

Distractor Phase

Test Phase
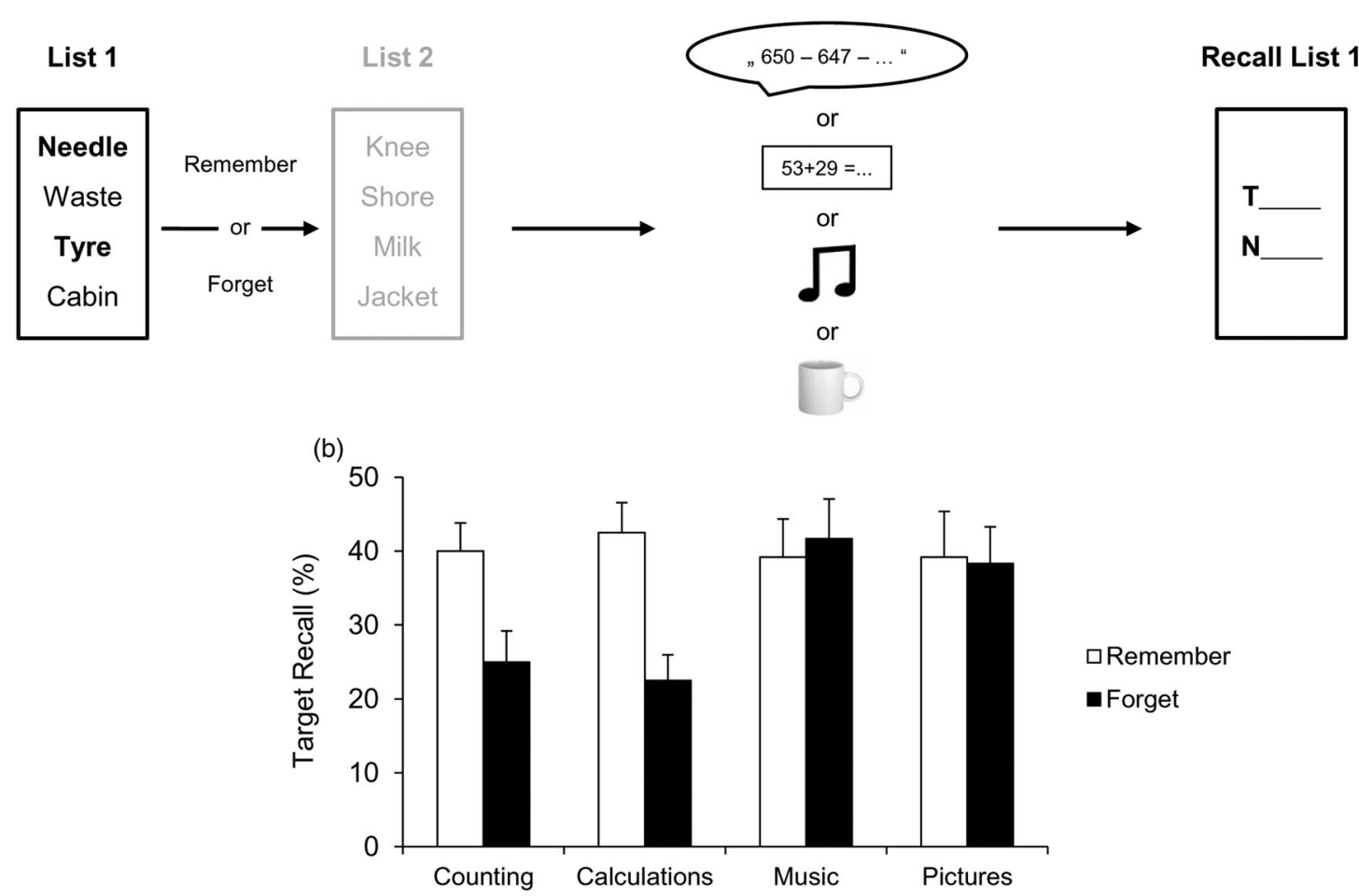

Figure 1. (a) Overview of the experimental procedure. In the study phase, participants studied two word lists. After study of List 1, participants received a cue to either forget or continue to remember that list. In the distractor phase, participants either counted backwards by threes, solved simple math calculations, listened to emotionally neutral music, or watched emotionally neutral pictures. In the test phase, participants were asked to recall predefined target words (boldface type) from List 1 (e.g., Needle, Tyre). (b) Mean target recall as a function of cue (remember vs. forget) and distractor task (counting vs. calculations vs. music vs. pictures). The error bars represent standard errors.

crash was simulated and participants were asked to forget the list and try remembering the upcoming list instead (e.g. Abel \& Bäuml, 2013). List-2 presentation was always followed by a cue to remember the list.

Distractor Phase. The subsequent retention interval lasted $72 \mathrm{~s}$. Participants in the counting condition were asked to count backwards by threes from a three digit number (e.g., 650, 647, ... ). In the calculations condition, they were asked to solve as many simple math calculations as possible (e.g., $53+29=\ldots$ ) on a sheet of paper. In the music condition, participants were told to relax and listen to a short piece of music; then they were presented with the first $72 \mathrm{~s}$ of one of the two instrumental pieces. Participants in the picture condition were also told to relax and were asked to contemplate 10 pictures for $6 \mathrm{~s}$ each, with a prestimulus interval of $2 \mathrm{~s}$ and an interstimulus interval of $1 \mathrm{~s}$.

Test Phase. After the retention interval, participants were asked to recall the first-list items. Target items were tested first and they were cued with their unique initial letter. The item cues were exposed successively, for $6 \mathrm{~s}$ each, and followed a random order. Participants gave their responses orally. Because the forget cue predominantly affects List1 items probed early at test (e.g., Bäuml \& Samenieh, 2010, 2012a), analysis of List-1 recall focused on the target items (see also Abel \& Bäuml, 2013). The remaining
List- 1 and the List-2 items were tested afterwards. The List2 items were cued with their unique initial letter, the remaining List-1 items with their word stems.

After a 5-min break, participants completed the second experimental block in the other cue condition. That is, if they had received a remember cue after List- 1 in the first experimental block, they received a forget cue in the second experimental block, and vice versa (e.g., Barnier et al., 2007; Conway \& Fthenaki, 2003; Zellner \& Bäuml, 2006). Participants in the counting condition started counting backwards from a different three digit number, and in the calculations condition, individuals solved different calculations. Participants in the music condition were presented with the other instrumental piece, and in the picture condition, individuals contemplated the other set of pictures.

\section{Results}

\section{Recall of list-1 target items}

Recall rates for target items are shown in Figure 1(b). A 2 (cue: remember, forget) x 4 (distractor task: counting, calculations, music, pictures) analysis of variance (ANOVA) revealed a significant main effect of cue, $F(1,92)=9.95$, $M S E=0.033, p=.002$, partial $\eta^{2}=.10$, reflecting overall 
directed forgetting, that is, lower recall in the forget than in the remember condition (31.9\% vs. $40.2 \%$ ), but no significant main effect of distractor task, $F(3,92)=1.11, M S E=$ $0.074, p=.35$, partial $\eta^{2}=.04$. Most important, a significant interaction between the two factors arose, $F(3,92)=4.23$, $M S E=0.033, p=.008$, partial $\eta^{2}=.12$, signifying that the forget cue affected recall differently depending on distractor task condition. Whereas directed forgetting was present in the counting condition ( $25.0 \%$ vs. $40.0 \%), t(23)$ $=3.09, p=.005, d=0.76$, and in the calculations condition $(22.5 \%$ vs. $42.5 \%), t(23)=4.29, p<.001, d=1.08$, the forget cue did not affect recall in the music condition $(41.7 \%$ vs. $39.2 \%), t(23)<1$, and the pictures condition (38.3\% vs. $39.2 \%), t(23)<1$. Recall of to-be-remembered target items was unaffected by distractor task condition, $F(3,92)<1$.

Regarding intrusions, no subject falsely recalled any second-list item when asked to recall first-list items. Cases of extra-list intrusions, that is, unstudied items which were falsely recalled during recall of the first-list items were rare $(M=0.8, S D=1.3)$ and there were no differences between distractor task or cue conditions, $p s>.130$.

In this experiment, one half of the participants completed the remember condition first, and the other half completed the forget condition first. Cue order did not affect target recall, as is indicated by a $2 \times 4 \times 2$ ANOVA with the additional factor of cue order (remember first, forget first). Such analysis showed no main effect of cue order, $F(1,88)=2.52, M S E=0.074, p=.116$, partial $\eta^{2}=.03$, no interaction between cue and cue order, $F(1,88)=2.53$,
MSE $=0.033, p=.115$, partial $\eta^{2}=.03$, no interaction between distractor task and cue order, $F(3,88)<1$, and particularly no significant three-way-interaction, $F(3,88)<1$.

\section{Recall of list-2 items}

Regarding recall performance for the List- 2 items in the remember and forget conditions, results showed recall rates of $43.1 \%(S E=5.2)$ and $48.1 \%(S E=5.1)$ in the counting condition, 55.6\% (SE = 4.7) and 49.2\% (SE =3.8) in the calculation condition, $53.1 \%(S E=5.4)$ and $60.0 \%$ (SE = $5.4)$ in the music condition, and $48.1 \%(S E=6.0)$ and $56.7 \%(S E=5.9)$ in the picture condition. A 2 (cue: remember, forget) $\times 4$ (distractor task: counting, calculations, music, pictures) ANOVA revealed no significant effects, all $p s>.110$. These results are consistent with prior work, showing that preceding recall of first-list items often eliminates possible effects of the forget cue on recall of secondlist items (e.g., Golding \& Gottlob, 2005; Pastötter, Kliegl, \& Bäuml, 2012). ${ }^{2}$

\section{Discussion}

The results show that the level of cognitive activity that subjects engage in shortly after new learning takes place influences directed forgetting. When subjects engage in "active" distractor tasks, like backward counting or math calculations, the forget cue reduces memory for to-be-forgotten items and directed forgetting arises. In contrast, when "passive" wakeful resting is induced during the

Table 1. Studies along with type of distractor task, duration of distractor task, percentage of list 1 forgetting and effect size of list 1 forgetting.

\begin{tabular}{|c|c|c|c|c|c|}
\hline Studies included in the meta-analysis & Distractor task & Duration & $\%_{F}$ & $d_{F}$ & $S\left(d_{F}\right)$ \\
\hline Aslan, Zellner, and Bäuml (2010, Experiment 1) & Counting & $90 \mathrm{~s}$ & 9 & 0.577 & 0.174 \\
\hline Pastötter and Bäuml (2007) & Counting & $30 \mathrm{~s}$ & 10 & 0.751 & 0.199 \\
\hline Pastötter and Bäuml (2010, Experiment 1, 15 item conditions) & Counting & $30 \mathrm{~s}$ & 16 & 1.225 & 0.272 \\
\hline Pastötter and Bäuml (2010, Experiment 2, 15 item conditions) & Counting & $30 \mathrm{~s}$ & 12 & 0.967 & 0.176 \\
\hline Pastötter and Bäuml (2010, Experiment 3, 15 item conditions) & Counting & $30 \mathrm{~s}$ & 18 & 0.849 & 0.246 \\
\hline Sahakyan, Delaney, and Goodmon (2008, Experiment 1) & Counting & $60 \mathrm{~s}$ & $\sim 15^{\mathrm{a}}$ & 1.090 & 0.268 \\
\hline Sahakyan et al. (2008, Experiment 2) & Counting & $60 \mathrm{~s}$ & $\sim 11^{\mathrm{a}}$ & 0.908 & 0.263 \\
\hline Sahakyan and Goodmon (2007, Experiment 1, unrelated conditions) & Counting & $90 \mathrm{~s}$ & 12 & 0.987 & 0.306 \\
\hline Sahakyan and Goodmon (2007, Experiment 2, unrelated conditions) & Counting & $90 \mathrm{~s}$ & 10 & 0.968 & 0.216 \\
\hline Sterzer, Schabus, Bäuml, and Kerschbaum (2015) & Counting & $30 \mathrm{~s}$ & 22 & 1.321 & 0.494 \\
\hline Zou, Zhang, Huang, and Weng (2011, Experiment 2, healthy controls) & Counting & $180 \mathrm{~s}$ & 12 & 0.513 & 0.371 \\
\hline Delaney and Sahakyan (2007, Experiment 1) & Calculations & $90 \mathrm{~s}$ & 20 & 1.121 & 0.229 \\
\hline Hupbach and Sahakyan (2014, matching conditions) & Calculations & $60 \mathrm{~s}$ & 11 & 0.801 & 0.300 \\
\hline Lehman and Malmberg (2009, Experiment 1) & Calculations & $30 \mathrm{~s}$ & 7 & 0.548 & 0.222 \\
\hline Lehman and Malmberg (2011, unrelated items) & Calculations & $30 \mathrm{~s}$ & $\sim 7^{\mathrm{a}}$ & 0.622 & 0.229 \\
\hline Minnema and Knowlton (2008, Experiment 1, neutral words) & Calculations & $60 \mathrm{~s}$ & $\sim 5^{\mathrm{a}}$ & 0.452 & 0.261 \\
\hline Mulji and Bodner (2010, Experiment 1) & Calculations & $90 \mathrm{~s}$ & 9 & 0.727 & 0.286 \\
\hline Racsmány et al. (2008, Experiment 1) & Calculations & $300 \mathrm{~s}$ & 18 & 0.813 & 0.380 \\
\hline Sahakyan and Kelley (2002, Experiment 1, standard conditions) & Calculations & $90 \mathrm{~s}$ & 11 & 0.542 & 0.217 \\
\hline Sahakyan and Kelley (2002, Experiment 2, not reinstated conditions) & Calculations & $90 \mathrm{~s}$ & 20 & 1.183 & 0.271 \\
\hline Whetstone, Cross, and Whetstone (1996) & Calculations & $120 \mathrm{~s}$ & $\sim 16^{\mathrm{a}}$ & 0.900 & 0.309 \\
\hline Zellner and Bäuml (2006, Experiment 1) & Calculations & $120 \mathrm{~s}$ & 16 & 0.833 & 0.363 \\
\hline Foster and Sahakyan (2011, overt conditions) & None & - & 9 & 0.469 & 0.227 \\
\hline Golding and Gottlob (2005, Experiment 2) & Drawing & $120 \mathrm{~s}$ & 12 & 0.722 & 0.337 \\
\hline Kimball and Bjork (2002, Experiment 1) & None & - & 12 & 0.630 & 0.187 \\
\hline Spillers and Unsworth (2011) & Ordering & $30 \mathrm{~s}$ & $\sim 12^{\mathrm{a}}$ & 0.839 & 0.295 \\
\hline Wessel and Merckelbach (2006, neutral conditions) & Concentration & $180 \mathrm{~s}$ & 18 & 1.095 & 0.287 \\
\hline
\end{tabular}

Note: Duration = duration of the distractor task; $\%_{F}=$ percentage of List 1 forgetting; $d_{F}=$ effect size of List 1 forgetting; $S\left(d_{F}\right)=$ estimated standard deviation of $d_{F}$.

a $=$ estimated from figure 
retention interval, as was the case in the present music condition and the pictures condition, the forget cue does not affect memory and no directed forgetting arises.

In LMDF, the forgetting of the precue items is often attributed to some form of contextual forgetting, assuming that the presentation of the forget cue impairs access to the items' study context (e.g., Bäuml \& Samenieh, 2010; Geiselman et al., 1983; Kimball \& Bjork, 2002; Sahakyan \& Kelley, 2002). On the basis of such view, wakeful resting immediately after encoding may attenuate the forgetting, because wakeful resting can reactivate the study episode (Dewar, Alber, Cowan, \& Della Sala, 2014; Tambini et al., 2010). Indeed, if reactivation of the study episode was more beneficial for the (previously deactivated) to-be-forgotten items than the (still activated) to-be-remembered items, then wakeful resting may improve mainly recall of the to-be-forgotten items, thus reducing directed forgetting. The results show exactly this pattern.

Instead of attributing the present results to reactivation processes, alternatively one may like to explain the results by context-change processes that may have been induced by the present music and picture presentations during the resting period. For instance, according to the contextchange account of LMDF, which assumes that the forget cue enhances the difference between the two list contexts, and the view that mental context fluctuates over time (e.g., Estes, 1955; McGeoch, 1932), a music- or pictures-induced context change may shift the context sufficiently far away from the list contexts, so that the difference between the two list contexts may become relatively small and List- 1 recall may no longer depend much on the originally induced mental context change, that is, the forgetting of List-1 items disappears (Divis \& Benjamin, 2014; Mensink \& Raaijmakers, 1988). Such proposal, however, does not only predict that List-1 forgetting should disappear when music or pictures are provided during the retention interval, but does also predict that List-1 recall in the remember condition should be impaired in the music and pictures conditions, relative to the counting and calculation conditions. While the first prediction is confirmed by the present results, the second prediction is not, which rules out a context-change explanation of the present resting finding.

An alternative to explain the present results may be rehearsal processes. The assumption would be that participants engage in intentional rehearsal of the to-be-forgotten items during resting and thus create recall improvement for these items on the later memory test. However, Dewar et al. (2014) reported that even (unrehearsable) nonwords (e.g., toijcunn) are better remembered after a period of wakeful resting than after an active distractor task, suggesting that wakeful resting can promote recall improvement even without intentional rehearsal of the study material. Moreover, it has been argued that, if rehearsal occurred during a retention interval, it should maintain or even enhance the forgetting effect (MacLeod, Dodd, Sheard, Wilson, \& Bibi, 2003). The view is that participants in the remember condition may rehearse List- 2 and List- 1 items, whereas participants in the forget condition selectively rehearse the List-2 items, anticipating that only those items will be tested later. The present results thus appear more easily explainable by attributing them to reactivation processes rather than attributing them to context-change or rehearsal processes. Of course, such proposal must remain speculative at this point, and further work is required to examine in more detail exactly which mechanism(s) mediate(s) the effect of brief wakeful resting on directed forgetting.

Previous studies showed that the effects of the forget cue can be reduced with a number of context reactivation techniques. Such techniques include many active processes, such as mental reinstatement of the precue study context (Sahakyan \& Kelley, 2002) or selective retrieval of some of the precue items (Bäuml \& Samenieh, 2010). Against this background, the recent finding that nocturnal sleep can eliminate directed forgetting (Abel \& Bäuml, 2013) provided first evidence that the effects of the forget cue can also be counteracted when memory processing is not subject to conscious control. The present results extend these findings even further by demonstrating that even a brief period of wakeful resting after encoding can be sufficient to attenuate the forgetting. Critically, sleep effects have been shown to emerge primarily if sleep follows closely upon encoding (e.g., Benson \& Feinberg, 1977; Gais, Lucas, \& Born, 2006; Talamini, Nieuwenhuis, Takashima, \& Jensen, 2008). Similarly, resting effects may presuppose that resting follows closely upon encoding. The present finding thus is not in conflict with Abel and Bäuml (2013) result that List-1 forgetting can persist for 12 hours of being awake. Although, in general, such long delay will include some wakeful resting, often the resting will not occur immediately after encoding.

Motivated by prior LMDF work, in which there was typically a short active distractor of 30-180 s between encoding and test (e.g., Geiselman et al., 1983; Pastötter \& Bäuml, 2010; Sahakyan \& Kelley, 2002), this study employed a resting period of $72 \mathrm{~s}$ after encoding, which was thus shorter than the 10-min period used in several previous resting studies (e.g., Dewar et al., 2012, 2014). On the one hand, the briefness of the present resting period provides an outstanding demonstration of the possible influence of even very short resting periods on memory performance. On the other hand, it may also be responsible for why there was no beneficial effect of resting on to-be-remembered items at all. If wakeful resting provides conditions of minimal interference during which the study episode can be replayed, then longer periods of resting may increase the number of such automatic replays, strengthening the memory traces to a larger extent than shorter periods (e.g., Dewar et al., 2014). If so, longer periods of resting may improve recall in LMDF even more than was observed in the present study, and also to-be-remembered items may profit from resting, though to a lesser extent than the (previously deactivated) to-be-forgotten items. 
Such finding would mimic the results of Abel and Bäuml (2013) sleep study.

The results of this study arrive at a time when LMDF research has typically been conducted using a very restrictive set of distractor tasks between study and test. Indeed, when taking a look at LMDF studies of the past 20 years, it turns out that most of the studies used either a variant of backward counting or a variant of performing calculations as distractor task (see Table 1). The mean effect size of List1 forgetting was similar between the two types of tasks (0.92 vs. $0.78 ; X^{2}(1)=1.28, p=.260$ ) and is similar to the effect size observed in the counting and calculations conditions of the present study (0.76 vs. 1.08). In particular, in all this prior research there is not a single case in which the retention interval was filled with any form of "passive" wakeful resting. The present study thus opens a new field for LMDF research, which may take a closer look at the role of distractor task for List-1 forgetting and examine the effects of "active" distractor tasks other than counting and calculations, and "passive" distractor tasks other than providing music and pictures. The findings from such work may provide new insights into the possible role of distractor task and resting in LMDF.

In brief, this is the first study to show that a brief period of wakeful resting can eliminate intentional forgetting. People were able to forget supposedly irrelevant material in the absence of a resting period shortly after study, whereas they were not able to do so in its presence. The findings demonstrate that the degree to which people can intentionally forget memories can be influenced by the cognitive activity that people engage in shortly after learning takes place.

\section{Notes}

1. Typically, the forget cue does not only reduce recall of the first list but does also improve recall of the second list (e.g., Geiselman et al., 1983). Because in this study the focus is exclusively on first-list recall, however, this effect is ignored here.

2. Regarding recall performance for the remaining List-1 items in the remember and forget conditions, results showed recall rates of $92.9 \%(S E=1.5)$ and $90.4 \%(S E=2.7)$ in the counting group, $93.3 \%(S E=1.4)$ and $90.4 \%(S E=2.0)$ in the calculation group, $92.5 \%(S E=2.5)$ and $93.8 \%(S E=2.1)$ in the music condition, and $95.0 \%(S E=1.7)$ and $90.0 \%(S E=2.5)$ in the pictures condition. Analysis of variance revealed no significant effects, all $p s>.080$. These results replicate prior work, showing that effects of the forget cue on List 1 recall are largely absent if the items' word stems are provided as retrieval cues at test (e.g., Bäuml \& Samenieh, 2010, 2012a).

\section{Disclosure statement}

No potential conflict of interest was reported by the authors.

\section{References}

Studies included in the meta-analysis (see Table 1) are marked with an asterisk $(*)$.
Abel, M., \& Bäuml, K.-H. T. (2013). Sleep can eliminate list-method directed forgetting. Journal of Experimental Psychology: Learning, Memory, \& Cognition, 39, 946-952.

(*) Aslan, A., Zellner, M., \& Bäuml, K.-H. T. (2010). Working memory capacity predicts listwise directed forgetting in adults and children. Memory, 18, 442-450.

Barnier, A. J., Conway, M. A., Mayoh, L., Speyer, J., Avizmil, O., \& Harris, C. B. (2007). Directed forgetting of recently recalled autobiographical memories. Journal of Experimental Psychology: General, 136, 301-322.

Bäuml, K.-H. T., \& Samenieh, A. (2010). The two faces of memory retrieval. Psychological Science, 21, 793-795.

Bäuml, K.-H. T., \& Samenieh, A. (2012a). Selective memory retrieval can impair and improve retrieval of other memories. Journal of Experimental Psychology: Learning, Memory, \& Cognition, 38, 388394.

Bäuml, K.-H. T., \& Samenieh, A. (2012b). Influences of part-list cuing on different forms of episodic forgetting. Journal of Experimental Psychology: Learning, Memory, and Cognition, 38, 366-375.

Benson, K. \& Feinberg, I. (1977). The beneficial effect of sleep in an extended Jenkins and Dallenbach paradigm. Psychophysiology, 14, 375-384.

Bjork, R. A. (1970). Positive forgetting: The noninterference of items intentionally forgotten. Journal of Verbal Learning \& Verbal Behavior, 9, 255-268.

Bjork, E. L., \& Bjork, R. A. (1996). Continuing influences of to be-forgotten information. Consciousness \& Cognition, 5, 176-196.

Conway, M. A., \& Fthenaki, A. (2003). Disruption of inhibitory control of memory following lesions to the frontal and temporal lobes. Cortex, 39, 667-686.

Cowan, N., Beschin, N., \& Della Sala, S. (2004). Verbal recall in amnesiacs under conditions of diminished retroactive interference. Brain, 127, 825-834.

(*) Delaney, P. F., \& Sahakyan, L. (2007). Unexpected costs of high working memory capacity following directed forgetting and contextual change manipulations. Memory \& Cognition, 35, 1074-1082.

Dewar, M. T., Alber, J., Butler, C., Cowan, N., \& Della Sala, S. (2012). Brief wakeful resting boosts new memories over the long term. Psychological Science, 23, 955-960.

Dewar, M. T., Alber, J., Cowan, N., \& Della Sala, S. (2014). Boosting longterm memory via wakeful rest: Intentional rehearsal is not necessary, consolidation is sufficient. PLOS ONE, 9, 10.

Diba, K., \& Buzsáki, G. (2007). Forward and reverse hippocampal placecell sequences during ripples. Nature Neuroscience, 10, 1241-1242.

Diekelmann, S., \& Born, J. (2010). The memory function of sleep. Nature Reviews Neuroscience, 11, 114-126.

Diekelmann, S., Wilhelm, I., \& Born, J. (2009). The whats and whens of sleep dependent memory consolidation. Sleep Medicine Reviews, 13, 309-321.

Divis, K. M., \& Benjamin, A. S. (2014). Retrieval speeds context fluctuation: Why semantic generation enhances later learning, but hinders prior learning. Memory \& Cognition, 42, 1049-1062.

Duyck, W., Desmet, T., Verbeke, L., \& Brysbaert, M. (2004). Wordgen: A tool for word selection and non-word generation in Dutch, German, English, and French. Behavior Research Methods, Instruments \& Computers, 36, 488-499.

Estes, W. K. (1955). Statistical theory of spontaneous recovery and regression. Psychological Review, 62, 145-154.

(*) Foster, N. L., \& Sahakyan, L. (2011). The role of forget-cue salience in list-method directed forgetting. Memory, 19, 110-117.

Gais, S., Lucas, B., \& Born, J. (2006). Sleep after learning aids memory recall. Learning \& Memory, 13, 259-262.

Geiselman, R. E., Bjork, R. A., \& Fishman, D. (1983). Disrupted retrieval in directed forgetting: A link with posthypnotic amnesia. Journal of Experimental Psychology: General, 112, 58-72.

(*) Golding, J. M., \& Gottlob, L. R. (2005). Recall order determines the magnitude of directed forgetting in the within-participants list method. Memory \& Cognition, 33, 588-594. 
(*) Hupbach, A., \& Sahakyan, L. (2014). Additional boundary condition for list-method directed forgetting: The effect of presentation format. Journal of Experimental Psychology: Learning, Memory, and Cognition, 40, 596-601.

$\left.{ }^{*}\right)$ Kimball, D. R., \& Bjork, R. A. (2002). Influences of intentional and unintentional forgetting on false memories. Journal of Experimental Psychology: General, 131, 116-130.

Lang, P. J., Bradley, M. M., \& Cuthbert, B. N. (1999). International Affective Picture System (IAPS): Technical manual and affective ratings. Gainesville, FL: University of Florida, Center for Research in Psychophysiology.

(*) Lehman, M., \& Malmberg, K. J. (2009). A global theory of remembering and forgetting from multiple lists. Journal of Experimental Psychology: Learning, Memory, and Cognition, 35, 970-988.

$\left(^{*}\right)$ Lehman, M., \& Malmberg, K. J. (2011). Overcoming the effects of intentional forgetting. Memory \& Cognition, 39, 335-347.

MacLeod, C. M., Dodd, M. D., Sheard, E. D., Wilson, D. E., \& Bibi, U. (2003). In opposition to inhibition. In B. H. Ross (Ed.), The psychology of learning and motivation (Vol. 43, pp. 163-214). San Diego, CA: Academic Press.

McGeoch, J. (1932). Forgetting and the law of disuse. Psychological Review, 39, 352-370. doi:10.1037/h0069819

Mensink, G., \& Raaijmakers, J. G. (1988). A model for interference and forgetting. Psychological Review, 95, 434-455.

$\left(^{*}\right)$ Minnema, M. T., \& Knowlton, B. J. (2008). Directed forgetting of emotional words. Emotion, 8, 643-652.

(*) Mulji, R., \& Bodner, G. E. (2010). Wiping out memories: New support for a mental context change account of directed forgetting. Memory, 18, 763-773.

Nairne, J. S., \& Healy, A. F. (1983). Counting backwards produces systematic errors. Journal of Experimental Psychology: General, 112, 37-40.

${ }^{*}$ ) Pastötter, B., \& Bäuml, K.-H. (2007). The crucial role of postcue encoding in directed forgetting and context-dependent forgetting. Journal of Experimental Psychology: Learning, Memory, \& Cognition, 33, 977-982.

(*) Pastötter, B., \& Bäuml, K.-H. (2010). Amount of postcue encoding predicts amount of directed forgetting. Journal of Experimental Psychology: Learning, Memory, \& Cognition, 36, 54-65.

Pastötter, B., Kliegl, O., \& Bäuml, K.-H. T. (2012). List-method directed forgetting: The forget cue improves both encoding and retrieval of postcue information. Memory \& Cognition, 40, 861-873.

(*) Racsmány, M., Conway, M. A., Garab, E. A., Cimmer, C., Janka, Z., Kurimay, T., ... Szendi, I. (2008). Disrupted memory inhibition in schizophrenia. Schizophrenia Research, 101, 218-224.

Rasch, B., \& Born, J. (2013). About sleep's role in memory. Physiological Reviews, 93, 681-766.

Rasch, B., Büchel, C., Gais, S., \& Born, J. (2007). Odor cues during slowwave sleep prompt declarative memory consolidation. Science, 315, 1426-1429.
Richell, R. A., \& Anderson, M. (2004). Reproducibility of negative mood induction: A self-referent plus musical mood induction procedure and a controllable/uncontrollable stress paradigm. Journal of Psychopharmacology, 18, 94-101.

Sahakyan, L., Delaney, P. F., Foster, N. L., \& Abushanab, B. (2013). Listmethod directed forgetting in cognitive and clinical research: $A$ theoretical and methodological review. In B. H. Ross (Ed.), The psychology of learning and motivation (Vol. 59, pp. 131-190). Amsterdam, The Netherlands: Elsevier.

(*) Sahakyan, L., Delaney, P. F., \& Goodmon, L. B. (2008). Oh, honey, I already forgot that: Strategic control of directed forgetting in older and younger adults. Psychology and Aging, 23, 621-633.

(*) Sahakyan, L., \& Goodmon, L. B. (2007). The influence of directional associations on directed forgetting and interference. Journal of Experimental Psychology: Learning, Memory, and Cognition, 33, 1035-1049.

$\left(^{*}\right)$ Sahakyan, L., \& Kelley, C. M. (2002). A contextual change account of the directed forgetting effect. Journal of Experimental Psychology: Learning, Memory, \& Cognition, 28, 1064-1072.

$\left(^{*}\right)$ Spillers, G. J., \& Unsworth, N. (2011). Are the costs of directed forgetting due to failures of sampling or recovery? Exploring the dynamics of recall in list-method directed forgetting. Memory \& Cognition, 39, 403-411.

(*) Sterzer, L., Schabus, M., Bäuml, K.-H. T., \& Kerschbaum, H. H. (2015) Intentional updating in episodic memory: Low testosterone associates with enhanced memory updating. Neuroendocrinology Letters, 36, 196-200.

Stickgold, R., \& Walker, M. P. (2013). Sleep-dependent memory triage: Evolving generalization through selective processing. Nature Neuroscience, 16, 139-145.

Talamini, L. M., Nieuwenhuis, I. L. C., Takashima, A., \& Jensen, O. (2008) Sleep directly following learning benefits consolidation of spatial associative memory. Learning \& Memory, 15, 233-237.

Tambini, A., Ketz, N., \& Davachi, L. (2010). Enhanced brain correlations during rest are related to memory for recent experiences. Neuron, 65, 280-290.

(*) Wessel, I., \& Merckelbach, H. (2006). Forgetting murder is not harder than forgetting circle: Listwise-directed forgetting of emotional words. Cognition \& Emotion, 20, 129-137.

(*) Whetstone, T., Cross, M. D., \& Whetstone, L. M. (1996). Inhibition, contextual segregation, and subject strategies in list method directed forgetting. Consciousness \& Cognition, 5, 395-417.

Wood, J. V., Saltzberg, J. A., \& Goldsamt, L. A. (1990). Does affect induce self-focused attention? Journal of Personality and Social Psychology, 58, 899-908.

(*) Zellner, M., \& Bäuml, K.-H. (2006). Inhibitory deficits in older adults: List-method directed forgetting revisited. Journal of Experimental Psychology: Learning, Memory, \& Cognition, 32, 290-300.

(*) Zou, Z., Zhang, J. X., Huang, X., \& Weng, X. (2011). Impaired directed forgetting in abstinent heroin addicts. Memory, 19, 36-44. 